\title{
Effect of Family-Oriented Health Education Program on Awareness, Adherence to Treatment and Control among Hypertensive Patients
}

\author{
Wael A. Zeid', Fathy A. Makledy'2, Mosleh A. Ismail', Hanan A. El Gammal' \\ Departments of ${ }^{1}$ Family Medicine, and ${ }^{2}$ Cardiology, Faculty of Medicine, Suez Canal University, Egypt
}

\begin{abstract}
Background: Hypertension is a major health problem in Egypt with low rates of awareness, adherence, and control. Family oriented health education program is needed to know the effect of family involvement on the outcome of hypertension. Aim of the study: to improve care provided to hypertensive patients in family practice settings. Subjects and methods: This study was conducted as an intervention study. The awareness, adherence to treatment and control of hypertension were assessed before and after the intervention program through a structured interview with hypertensive patients and their families (at least one family member attended once/month over 6 months). The study was conducted at two family practice settings (the family practice outpatient clinic and El Mahsama family practice center, both are affiliated to Suez Canal University, Egypt). There were 206 hypertensive patients, who were recruited to reach the estimated sample size (190 patients) to start the intervention program. Results: The overall awareness, adherence, and control before the intervention were $60.2 \%, 37.1 \%$, and $12.9 \%$ respectively. One month after the end of the intervention program, all non-aware patients became aware $(p<0.001)$ and the pre-post adherence and BP control improved significantly ( $p<0.01$ and $p<0.001$ respectively). The rural residence and adherence improvement were statistically significant positive predictors of improvement of hypertension control. Conclusion: The family oriented-health education program is effective to improve awareness, adherence, and control of hypertension.
\end{abstract}

Keywords: Hypertension, Adherence, Control, Family oriented, Health education

\section{Introduction}

The detection and control of hypertension is a major public health challenge ${ }^{(1)}$. Up to three-quarters of the world's hypertensive population will be in developing countries by the year $2025^{(2)}$, and Egypt is one of these developing countries. The prevalence of hypertension in Egypt is $26.3 \%$ with low rates of awareness (37.5\%), adherence (23.9\%), and control $(8 \%)^{(3)}$. The Healthy
People 2010 report targets a control rate of $50 \%$ within 5 years, which would be reached if at least $80 \%$ of hypertensive individuals will be aware of their condition, $90 \%$ will be treated, and $70 \%$ of those treated will be controlled ${ }^{(4,5)}$. The chronic care model puts emphasis on the involvement of the community as well as the family members in the management plan ${ }^{(6)}$. Behavioral risk factors tend to cluster within families because members share similar 
diets, physical activities, and tobacco use ${ }^{(7)}$. Studies on family involvement were conducted on children and adolescents with chronic medical diseases ${ }^{(8,9)}$, as well as caregivers of elderly individuals with dementia, stroke, or cancer, or those undergoing palliative care ${ }^{(10)}$. Little attention, however, has been paid to the effect of family involvement on chronic physical diseases among adults. To the best of my knowledge, this is the first study discussing the effect of family oriented care on a chronic disease in Egypt.

\section{Subjects and Methods}

Patients with hypertension (BP $\geq 140 / 90$ $\mathrm{mmHg}$ ) were recruited from two family practice settings (the family practice outpatient clinic and El Mahsama Family practice center, which are both affiliated to Suez Canal University, Egypt). These settings were selected because both of them provide a comprehensive care to patients with chronic diseases (e.g. hypertension) as well as they are the sites of the researcher's work (which give more accessibility). Patients $>18$ years, both genders, with essential hypertension and mentally competent were included in the study, while pregnant and patients with history of disabling complications (e.g. stroke, end stage renal disease, retinopathy) were excluded because of pregnancy induced hypertension and inability to participate in the program respectively. A convenience sample was conducted, from which 206 hypertensive patients were recruited until the calculated sample size (190 participants) of unaware, non-adherent, and uncontrolled hypertensive patients was fulfilled. The participants and their families (At least one family member attended once/month over 6 months) were interviewed to assess socio-demographic, dis- ease and medication characteristics, as well as patient's awareness and family member's role. The modified Hill-Bone compliance scale, which is a valid tool in English, was translated into Arabic and used to assess the level of adherence. It is comprised of 10 items. Responses ranged from none of the time (scoring 1) to all of the time (scoring 4), so adherence scores of 10 indicated perfect adherence and greater than 10 indicated imperfect adherence ${ }^{(11,12)}$. Blood pressure was measured according to a standard method to assess BP control $(\mathrm{BP}<140 / 90)^{(13)}$. The health education program was conducted once/ month for 6 months, using different educational methods e.g. discussions, counseling and distribution of materials. The contents of the program were tailored according to each patient's level of knowledge and based on social cognitive theory ${ }^{(14)}$. Pilot study was conducted on 20 patients (not included in the sample) to ensure understandability and relevance of the questions. An intervention study was used in which awareness, adherence to treatment and control of hypertension were assessed before and after the intervention program. Figure( 1 )gives additional details about the steps.

\section{Operational definitions}

Awareness: is based on the subjects report of a prior diagnosis of hypertension made by a health professional ${ }^{(12)}$.

Adherence: is defined as the extent to which a person's behavior-taking medication, following a diet, and/or executing lifestyle changes-corresponds with agreed recommendations from a health care provider $^{(21)}$.

Control of hypertension: defined as pharmacological treatment associated with SBP $<140 \mathrm{mmHg}$ and a DBP $<90 \mathrm{mmHg}^{(14)}$. 


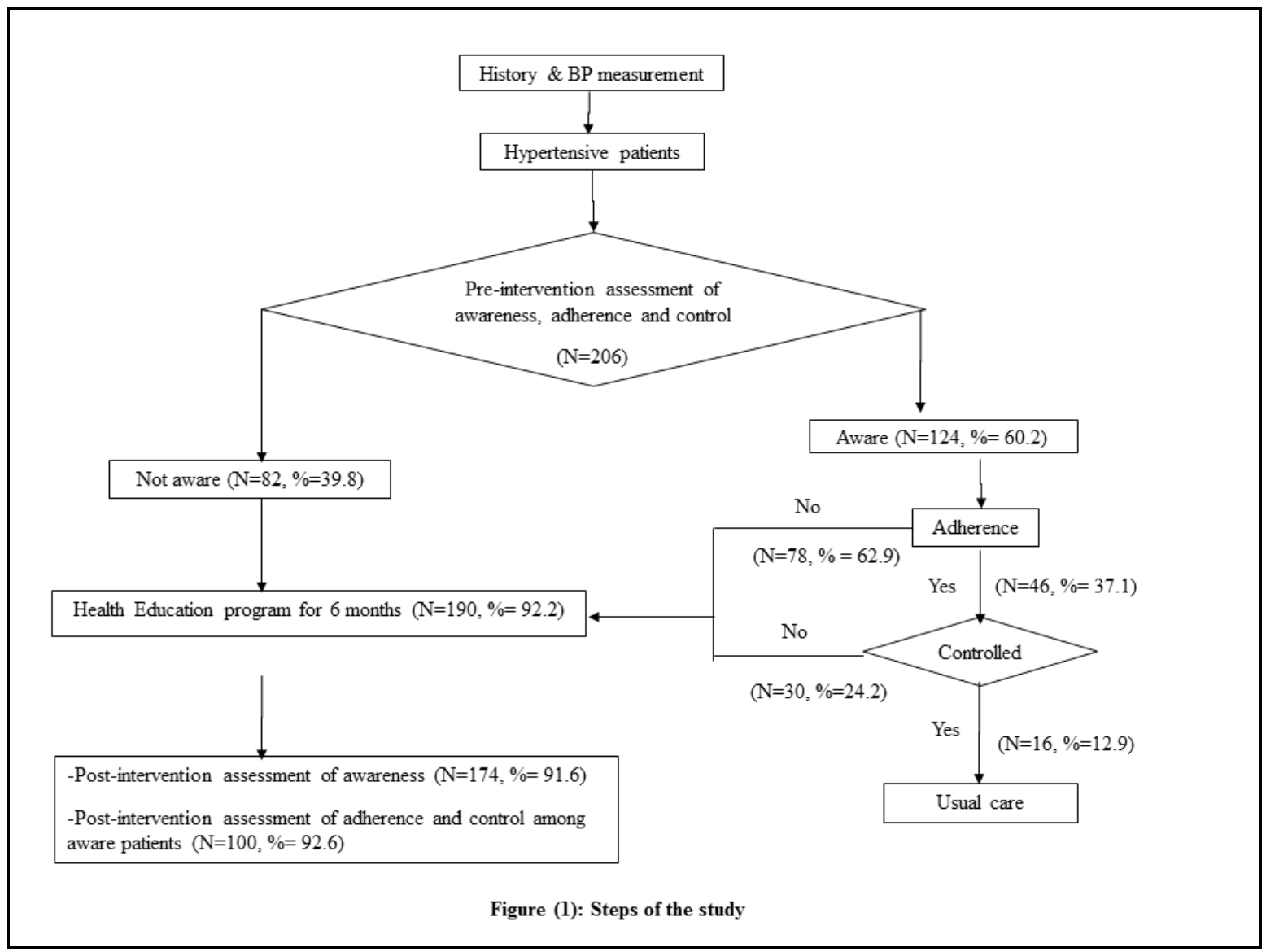

\section{Statistical Analysis}

The statistical package for social sciences (SPSS 20.0.0) was used for analysis of data. Descriptive tables in the form of frequencies and percentages were used for qualitative variables, and means and standard deviations for quantitative variables. Prepost results were compared using chisquare test. P-value <0.05 was considered statistically significant.

\section{Results}

The total sample before the intervention was 206 hypertensive patients in which the overall awareness, adherence and control before the intervention were $60.2 \%$ (124 out of 206 patients), 37.1\% (80/124 aware patients) and 12.9\% (16/124 aware patients) respectively. Table 1 demonstrates the socio-demographic, disease and medication characteristics of patients who participated in the study before intervention. The mean age was $54.3 \pm 8.2$, with a range between 40-80 years. Female patients represented $51.5 \%$ and less than two-thirds (63.1\%) were illiterate or had basic education; also less than two thirds were married (64.1\%). The non-employed patients (house wives, retired and non-employed) represented $52.9 \%$. About half of patients $(51 \%)$ had insufficient income, while the non-smokers represented $54.9 \%$. More than half of patients (53.4\%) had no co-existing diseases. The duration since diagnosis was from 5-10 years in $47.6 \%$ of patients. More than half of patients (53.2\%) received two or more medications, while less than two-thirds (62.9\%) received two or more doses per 
day. The medications were covered by health insurance in about two thirds of patients (64.5\%) and more than two thirds (68\%) had a positive family history. The response rate was $91.6 \%$ (174 participants), in which the post-intervention assessment for awareness was conducted, while the postintervention assessment for adherence, and control was conducted on aware patients only (100 patients). Table 2 illustrates the pre-post awareness, adherence, and control of hypertension among patients who participated in the intervention. According to the table, awareness of hypertension has shown a statistically significant improvement, $p<0.001$. Thus, before the intervention only more than half (57.5\%) were aware. This improved to $100 \%$ awareness after the intervention. In addition, the adherence among hypertensive patients who participated in the intervention has shown a statistically significant improvement $(P=0.01)$. The imperfect adherence had been improved from $24 \%$ before the intervention to $58 \%$ after the intervention. Furthermore, $100 \%$ of the participants had uncontrolled BP. This was reduced to $84 \%$ after the intervention. This improvement is statistically significant, $p<0.001$.

\section{Discussion}

Awareness rate in the total study sample was $60.2 \%$ which is higher than that reported in the Egyptian national survey conducted between 1991-1993 and the national Saudi survey $(37.5 \%, 44.7 \% \text { respectively })^{(3,16)}$. In explaining this difference, this study is a health care setting-based study, where more people are health care seekers, which resulted in more awareness, adherence, and control, while the other studies were community based, where asymptomatic patients are less aware.

\begin{tabular}{|c|c|c|}
\hline Characteristics & Frec & \\
\hline & No. & $\%$ \\
\hline Gender & & \\
\hline - Male & 100 & 48.5 \\
\hline - Female & 106 & 51.5 \\
\hline Age & & \\
\hline - Range & & \\
\hline$-\quad$ Mean \pm SD & 54. & \\
\hline Marital status & & \\
\hline - Single & 17 & 8.3 \\
\hline - Married & 132 & 64.1 \\
\hline - Widow & 55 & 26.7 \\
\hline - Divorced & 2 & 1 \\
\hline Educational level* & & \\
\hline - Level 0-2 & 130 & 63.1 \\
\hline - $\quad$ Level 3-5 & 56 & 27.2 \\
\hline - Level 6-8 & 20 & 9.7 \\
\hline Occupation & & \\
\hline - Employed & 97 & 44.9 \\
\hline - Unemployed & 109 & 55.1 \\
\hline Perceived income & & \\
\hline - Sufficient & 101 & 49 \\
\hline - Insufficient & 105 & 51 \\
\hline Smoking & & \\
\hline - Smoker & 93 & 45.1 \\
\hline - $\quad$ Non- smoker & 113 & 54.9 \\
\hline Co-morbidities & & \\
\hline - Yes & 96 & 46.6 \\
\hline$-\quad$ No & 110 & 53.4 \\
\hline Family history & & \\
\hline - Positive & 140 & 68 \\
\hline - Negative & 66 & 32 \\
\hline Duration (years) & & \\
\hline$-<5$ & 36 & 29 \\
\hline - $\quad 5-10$ & 59 & 47.6 \\
\hline$-10+$ & 29 & 23.4 \\
\hline No. of medications & & \\
\hline-1 & 58 & 46.8 \\
\hline$-2+$ & 66 & 53.2 \\
\hline No. of daily doses & & \\
\hline-1 & 46 & 37.1 \\
\hline$-2+$ & 78 & 62.9 \\
\hline Insurance coverage & & \\
\hline - Insured & 80 & 64.5 \\
\hline - $\quad$ Not insured & 44 & 35.5 \\
\hline
\end{tabular}

*Level 0-2: no education, primary or preparatory education; level 3-5: secondary, post secondary education or technical programs; level 6-8: bachelor, master, or doctoral degree ${ }^{(15)}$. 
Table 2: Pre-post awareness, adherence, and control among hypertension patients in the sample who participated in the intervention

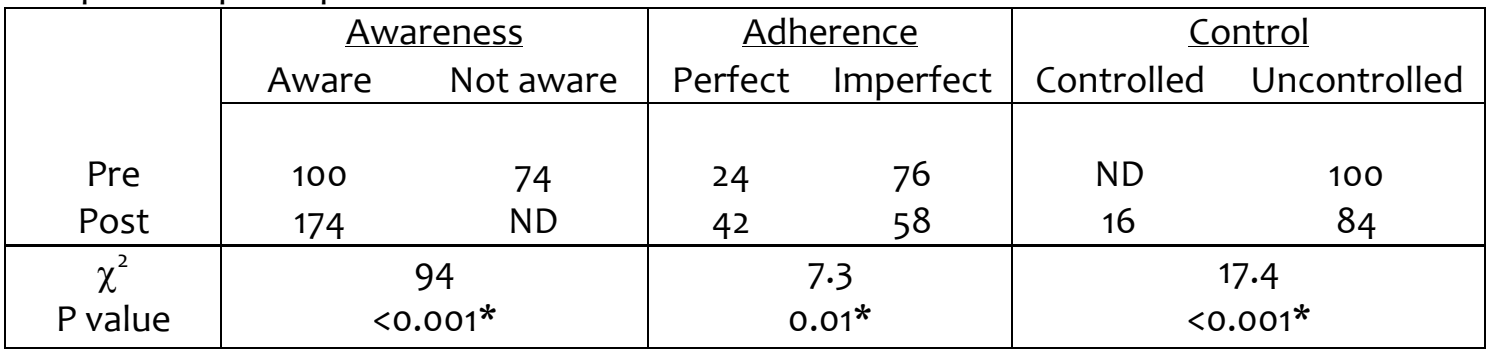

$\mathrm{ND}=$ Not Detected; * statistically significant at $\mathrm{P}<0.05$.

On the other hand this finding is lower than awareness rates in the US 2009-2010 $(81.9 \%)$ and Zaria, Nigeria $(71.1 \%)^{(17,18)}$. In the current study $37.1 \%$ of the aware patients in the total study sample were adherent, while only $12.9 \%$ were controlled. These results were higher than those reported in the Egyptian national survey $(23.9 \%$ and $8 \%$ for adherence and control correspondingly $)^{(3)}$. This is explained by the higher awareness rates in our study in comparison with other studies

The results of this study are not satisfactory in comparison with the US recording $76.4 \%$ and $53.3 \%$ for adherence and control respectively between $2009-2010^{(17)}$. In addition adherence and control rates were better in Saudi Arabia $72 \%$ and $37 \%$ respective$\mathrm{ly}^{(19)}$. However, our results were comparable with Seychelles which is a developing country (34\% adherence, and 10\% controlled $)^{(20)}$. The difference between developed and developing countries in many aspects, e.g. socio-economic status, could explain this. In the present study, the prepost awareness, adherence, BP control among patients in the total sample was analyzed. All non-aware patients became aware about hypertension, and this improvement was statistically significant $(p<0.001)$. This is in line with previous findings in the literature, which show that pa- tient education programs can be utilized to increase patients' awareness about hypertension ${ }^{(21-23)}$. The pre-post adherence has shown a statistically significant improvement after the intervention $(p=0.01)$. This could be due to the improvement in the level of awareness. However, WHO reported that information alone is not enough for creating or maintaining good adherence habits $^{(23)}$. In addition, two other studies showed no improvement in adherence levels after an educational intervention ${ }^{(23,24)}$. The BP control has shown also a statistically significant improvement after the intervention $(p<0.001)$.

This coincides with many studies showing the effect of health education programs with different approaches to patients, families, health professionals and community in Australia, Iran, Spain, USA and Brazil which revealed better blood pressure control rates ${ }^{(24-29)}$. This conflicting results may be explained by using different approaches of interventions to improve awareness, adherence and control (e.g. education in self-management; pharmacy management programs; nurse, pharmacist and other non-medical health professional intervention protocols; counseling; behavioral interventions; follow-up and reminders, among others). Also, in a landmark study conducted by Morisky et $\mathrm{al}^{(30)}$, pa- 
tients were assigned to three adherencepromoting interventions: physician counseling, family support for monitoring pill taking, group sessions with a social worker or to a control group. The 5-year analysis showed a continuing positive effect on appointment keeping, weight control, and blood-pressure control in the intervention groups. Study patients assigned to any of the experimental groups displayed a statistically significant $30 \%$ increase in BP control at the two-year follow-up, and a statistically significant $65 \%$ increase in BP control over the five-year period. Analysis of the main effects of the educational program demonstrated that the family member support intervention accounted for the greatest decrease in diastolic blood pressure variability ${ }^{(30)}$.

\section{Conclusions}

Interventions focused on family oriented care might be a successful approach to improving the management of hypertension. The care of patients with chronic diseases should be shifted from addressing only the individual patient to addressing the broader social context in which the patient lives and in which the disease is managed. The study recommends raising the awareness of diseases by health education programs, Family support should be encouraged to improve the outcome of diseases. Health care providers should mange chronic diseases in a familial context. Further studies can be carried out over a longer period to investigate whether or not this will have long-term effect on participants' levels of adherence and health outcomes.

\section{Limitations of the Study}

Some participants were accompanied by a family member however, we confirm that the patient should accompany the same family member every session, and that the contents of the missed session to be summarized to the main family member. Furthermore, the participants were highly selected patients attending a health care setting. Therefore, the results of this study cannot be extrapolated to other patients.

\section{References}

1. Hajjar I, Kotchen TA. Trends in prevalence, awareness, treatment, and control of hypertension in the United States, JAMA. 2003; 290 (2): 199-206.

2. Kearney $P M$, Whelton $M$, Reynolds $K$, Muntner P, Whelton PK, He J. Global burden of hypertension: analysis of worldwide data, Lancet. 2005; 365 (9455):217-223.

3. Ibrahim MM, Rizk H, Apple LJ, el Aroussy W, Helmy S, Sharaf Y, Ashour Z, Kandil H, Roccella E, Whelton PK. Hypertension, prevalence, awareness, treatment and control in Egypt. Results from the Egyptian National hypertension Project (NHP). Hypertension. 1995; 26 (6 pt 1):886- 890.

4. US Department of Health and Human Services. Healthy People 2010. 2nd ed. Will behington, DC: US Government Printing Office; 2000.

5. Egan BM, Basile JN. Controlling blood pressure in $50 \%$ of all hypertensive patients: an achievable goal in the healthy people 2010 report? J Invest Med. 2003; $51(6): 373-385$.

6. Bodenheimer T, Wagner EH, Grumbach K. Improving primary care for patients with chronic illness: the chronic care model, Part 2. JAMA 2002; 288(15): 19091914.

7. Doherty WJ, Campbell TL. Families and Health. Thousand Oaks CA: sage publications, 1988; p. 159.

8. Murphy HR, Rayman G, Skinner TC. Psycho- educational interventions for children and young people with type 1 diabetes. Diabet Med 2006; 23 (9): 935-943.

9. Park EW, Schultz JK, Tudiver F, Campbell $\mathrm{T}$, Becker L. Enhancing partner support to improve smoking cessation. Cochrane Database Syst Rev 2004; 3:CDo02928. 
Table 3: Relation between characteristics of patients in the total study sample and adherence to treatment after intervention $(n=100)$

\begin{tabular}{|c|c|c|c|c|}
\hline \multirow[b]{2}{*}{ Characteristics } & \multicolumn{2}{|c|}{ Adherence } & \multirow[t]{2}{*}{$\chi^{2}$} & \multirow[t]{2}{*}{ P value } \\
\hline & $\begin{array}{l}\text { Perfect } \\
\text { No. (\%) }\end{array}$ & $\begin{array}{c}\text { Imperfect } \\
\text { No. (\%) }\end{array}$ & & \\
\hline Gender & & & 7.8 & $0.005^{*}$ \\
\hline Male & $18(42.9)$ & $41(70.7)$ & & \\
\hline Female & $24(57.1)$ & $17(29 \cdot 3)$ & & \\
\hline Age $($ Mean \pm SD $)$ & $57.2( \pm 8.9)$ & $56.5( \pm 8.5)$ & $0.4^{@}$ & 0.7 \\
\hline Educational level & & & 1.04 & 0.6 \\
\hline Level 0-2 & $24(57.1)$ & $29(50)$ & & \\
\hline Level 3-5 & $14(33.3)$ & $25(43.1)$ & & \\
\hline Level 6-8 & $4(9.5)$ & $4(6.9)$ & & \\
\hline Marital status & & & 6.5 & 0.09 \\
\hline Single & 0 & $7(12.1)$ & & \\
\hline Married & $26(61.9)$ & $33(56.9)$ & & \\
\hline Widow\& divorced & $16(38.1)$ & $18(31)$ & & \\
\hline Occupation & & & 2.2 & 0.1 \\
\hline Employed & $14(33.3)$ & $28(48.3)$ & & \\
\hline Unemployed & $28(66.7)$ & $30(51.7)$ & & \\
\hline Perceived income & & & 7.1 & $0.008^{*}$ \\
\hline Sufficient & $14(33 \cdot 3)$ & $35(60.3)$ & & \\
\hline Insufficient & $28(66.7)$ & $23(39.7)$ & & \\
\hline Smoking & & & 15.1 & $<0.001^{*}$ \\
\hline Smoker & $14(33.3)$ & $42(72.4)$ & & \\
\hline None & $28(66.7)$ & $16(27.6)$ & & \\
\hline Co-morbidities & & & 4.8 & $0.03^{*}$ \\
\hline Yes & $26(61.9)$ & $23(39.7)$ & & \\
\hline No & $16(38.1)$ & $35(60.3)$ & & \\
\hline Family history & & & 8.7 & $0.003^{*}$ \\
\hline Positive & $27(64.3)$ & $20(34.5)$ & & \\
\hline Negative & $15(35.7)$ & $38(65.5)$ & & \\
\hline Duration (years) & & & 0.96 & 0.6 \\
\hline$<5$ & $9(21.4)$ & $13(22.4)$ & & \\
\hline $5-$ & $20(47.6)$ & $32(55.2)$ & & \\
\hline $10+$ & $13(31)$ & $13(22.4)$ & & \\
\hline No. of medications & & & 1.1 & 0.3 \\
\hline 1 & $24(57.1)$ & $27(46.6)$ & & \\
\hline $2+$ & $18(42.9)$ & $31(53.4)$ & & \\
\hline No. of daily doses & & & 11.1 & $0.001 *$ \\
\hline 1 & $23(54.8)$ & $13(22.4)$ & & \\
\hline $2+$ & $19(45.2)$ & $45(77.6)$ & & \\
\hline Insurance coverage & & & 0.2 & 0.6 \\
\hline Insured & $27(64 \cdot 3)$ & $40(69)$ & & \\
\hline Not insured & $15(35.7)$ & $18(31)$ & & \\
\hline Perceived role of family member & & & 2.6 & 0.1 \\
\hline Supportive & $22(52.4)$ & $21(36.2)$ & & \\
\hline Non-supportive & $20(47.6)$ & $37(63.8)$ & & \\
\hline
\end{tabular}

*=Statistically significant at $\mathrm{P}<0.05 ;{ }^{@}=$ t-test. 
Table 4: Characteristics of patients and hypertension control after intervention ( $\mathrm{N}=100)$.

\begin{tabular}{|c|c|c|c|c|}
\hline \multirow{2}{*}{ Characteristics } & \multicolumn{2}{|c|}{ Control } & \multirow[b]{2}{*}{$\chi^{2}$} & \multirow[b]{2}{*}{$P$ value } \\
\hline & Yes & No & & \\
\hline Gender & & & 6.1 & $0.01 *$ \\
\hline Male & $5(31.2)$ & $54(64 \cdot 3)$ & & \\
\hline Female & $11(68.8)$ & $30(35.7)$ & & \\
\hline Age (Mean \pm SD) & $54.3( \pm 6.8)$ & $57.1( \pm 8.8)$ & $-1.2^{@}$ & 0.2 \\
\hline Educational level & & & 6.4 & $0.04^{*}$ \\
\hline Level 0-2 & $13(81.2)$ & $40(47.6)$ & & \\
\hline Level 3-5 & $3(18.8)$ & $36(42.9)$ & & \\
\hline Level 6-8 & $0(0)$ & $8(9.5)$ & & \\
\hline Marital status & & & 1.7 & 0.6 \\
\hline Single & $0(0)$ & $7(8.3)$ & & \\
\hline Married & $10(62.5)$ & $49(58.3)$ & & \\
\hline Widow\& divorced & $6(37.5)$ & $28(33.3)$ & & \\
\hline Occupation & & & 4.2 & $0.04^{*}$ \\
\hline Employed & $3(18.8)$ & $39(46.4)$ & & \\
\hline Unemployed & $13(81.2)$ & $45(53.6)$ & & \\
\hline Perceived income & & & 2.4 & 0.1 \\
\hline Sufficient & $5(31.2)$ & $44(52.4)$ & & \\
\hline Insufficient & $11(68.8)$ & $40(47.6)$ & & \\
\hline Smoking & & & 1.2 & 0.3 \\
\hline Smoker & $7(43.8)$ & $49(58.3)$ & & \\
\hline None & $9(56.2)$ & $35(41.7)$ & & \\
\hline Co-morbidities & & & 4.4 & $0.04^{*}$ \\
\hline Yes & 4(25) & $45(53.6)$ & & \\
\hline No & $12(75)$ & $39(46.4)$ & & \\
\hline Family history & & & 6 & $0.014^{*}$ \\
\hline Positive & $12(75)$ & $35(41.7)$ & & \\
\hline Negative & $4(25)$ & $49(58.3)$ & & \\
\hline Duration (years) & & & 9.1 & $0.001 *$ \\
\hline$<5$ & $2(12.5)$ & $20(23.8)$ & & \\
\hline $5^{-}$ & $5(31.2)$ & $47(56)$ & & \\
\hline $10+$ & $9(56.2)$ & $17(20.2)$ & & \\
\hline No. of medications & & & 0.008 & 0.9 \\
\hline 1 & $8(50)$ & $43(51.2)$ & & \\
\hline $2+$ & $8(50)$ & $41(48.8)$ & & \\
\hline No. of daily doses & & & 0.02 & 0.9 \\
\hline 1 & $6(37.5)$ & $30(35.7)$ & & \\
\hline $2+$ & $10(62.5)$ & $54(64.3)$ & & \\
\hline Insurance coverage & & & 0.5 & 0.5 \\
\hline Insured & $12(75)$ & $55(65.5)$ & & \\
\hline Not insured & $4(25)$ & $29(34.5)$ & & \\
\hline Perceived role of family member & & & 9 & $0.003^{*}$ \\
\hline Supportive & $16(100)$ & $52(61.9)$ & & \\
\hline Non-supportive & 0 & $32(38.1)$ & & \\
\hline
\end{tabular}

Data are presented as No. (\%); * =statistically significant at $\mathrm{p}<0.05 ;{ }^{@} \mathrm{t}$-test.

10. Reinhard SC, Given B, Petlick NH, Bemis A. Supporting Family Caregivers in Providing Care. Patient Safety and Quality: An Evidence-Based Handbook for Nurses. Hughes RG, editor. Rockville
(MD): Agency for Healthcare Research and Quality (US); Apr. 2008, chapter 14.

11. Lambert EV, Steyn K, Stender S, Everage N, Fourie JM, Hill M. Crosscultural validation of the hill-bone 
compliance to high blood pressure therapy scale in a South African, primary healthcare setting. Ethn Dis. 2006; 16(1):286-91.

12. Kim MT, Hill MN, Bone LR, Levine DM. Development and testing of the HillBone compliance to high blood pressure therapy scale. Prog Cardiovasc Nurs. 2000;15 (3): 90-96.

13. Molarius A, Tuomilehto A, Kuulasmaa K. Quality Assessment of Data on Hypertension Control in the WHO MONICA Project, 1998. http:// www.ktl.fi/publications/monica/hypert en/hbpdrug.htm

14. Rimer B, Glanz K. Theory at a glance. A guide for health promotion practice, 2nd ed. US Department of Health and Human Services, NIH, 2005. http://www.cancer. gov/cancertopics/ cancerlibrary/theory.

15. UNESCO. International Standard Classification of Education (ISCED) 2011. http://www.uis.unesco.org/Education/ Documents/isced-2011-en.pdf

16. Saeed AA, Al-Hamdan NA, Bahnass AA, Abdalla AM, Abbas MA, Abuzaid LZ. Prevalence, Awareness, Treatment, and Conrol of Hypertension among Saudi Adult Population: A National Survey. Int J Hypertens 2011 (2011), Article ID 174135.

17. Yoon SS, Burt V, Louis T, Carroll MD. Hypertension among adults in the United States, 2009-2010. NCHS data brief, 2012; 107: 1-8.

18. Oyati A, Orogade AA, Danbauchi SS, Azuh PC. Awareness, Treatment and Control of Hypertension among Hypertensives in Zaria. J Med in Tropics. 2011; 13:2: 139-144.

19. Prince MJ, Ebrahim S, Acosta D, Ferri $C P$, Guerra $M$, Huang $Y$, et al. Hypertension prevalence, awareness, treatment and control among older people in Latin America, India and China: a 10/66 cross-sectional population-based survey. J Hypertens. 2012 Jan;30(1):177-87.
20. Bovet P, William J, Viswanathan B, Madeleine $G$, Romain S, Yerly $P$, Paccaud F, Gabriel A. The Seychelles Heart Study 2004: methods and main findings. Victoria, Seychelles: Ministry of Health and Social Development, 2007.

21. Roca B, Nadal E, Rovira RE, Valls S, Lapuebla C, Lloria N. Usefulness of a hypertension education program. South Med J 2003; 96(11):1133-1137.

22. Estrada D, Pujol $E$, Jiménez L, Salamero $M$, de la Sierra A. Effectiveness of an educational intervention on hypertension directed at elderly hypertensive patients. Rev Esp Geriatr Gerontol. 2012 ;47(2):6266.

23. Shiri C. Patient Education: The effect on patient behavior. Msc thesis, Faculty of Pharmacy, Rhodes University, Grahamstown. 2006.

24. Perl S, Riegelnik V, Mrak P, Ederer H, Rakovac I, Beck P, Kraler E, Stoff I, Winklehner S, Klima G, Pieske BM, Pieber TR, Zweiker R. Effects of a multifaceted educational program on blood pressure and cardiovascular risk in hypertensive patients: the Austrian herz.leben project. J Hypertens. 2011 ;29(10):2024-2030.

25. Khosravi A, Mehr GK, Kelishadi R, Shirani S, Gharipour M, Tavassoli A, Noori F, Sarrafzadegan N. The impact of a 6-year comprehensive community trial on the awareness, treatment and control rates of hypertension in Iran: experiences from the Isfahan healthy heart program. BMC Cardiovasc Disord. 2010, 10:61

26. Ribeiro AG, Ribeiro SM, Dias $C M$, Ribeiro AQ, Castro FA, Suárez-Varela MM, Cotta RM. Non-pharmacological treatment of hypertension in primary health care: A comparative clinical trial of two education strategies in health and nutrition. BMC Public Health 2011, 11:637. 
27. Fortmann SP, Winkleby MA, Flora JA, Haskell WL, Taylor CB. Effect of longterm community health education on blood pressure and hypertension control. The Stanford Five-City Project. Am J Epidemiol. 1990; 132(4):629-646.

28. Rigsby BD. Hypertension improvement through healthy lifestyle modifications. ABNF J. $2011 ; 22(2): 41-43$.

29. Ferrán $M M$, Casabella $A B$, Parcet $S J$, Fernández Ferré LI, de la Torre Castañeda M. Health education in arterial hypertension: the evaluation of a course aimed at poorly controlled hypertensives. Aten Primaria. 1990; 7(3):194, 196-198.

30. Morisky DE, Levine DM, Green LW, Shapiro S, Russell RP, Smith CR. Five-year blood pressure control and mortality following health education for hypertensive patients. Am J Public Health, 1983, 73 (2):153-162. 